\title{
INFLUENCE OF THE STRUCTURE OF SEERSUCKER WOVEN FABRICS ON THEIR FRICTION PROPERTIES
}

\author{
Łukasz Frącczak ${ }^{1}$, Małgorzata Matusiak ${ }^{2, *}$ \\ 1 Faculty of Mechanical Engineering, Institute of Machine Tools and Production Engineering, Lodz University of Technology, Lodz, Poland \\ 2 Faculty of Material Technologies and Textile Design, Institute of Architecture of Textiles, Lodz University of Technology, Lodz, Poland \\ ${ }^{*}$ Corresponding author. E-mail: malgorzata.matusiak@p.lodz.pl
}

\begin{abstract}
:
Friction is defined as a force resisting a relative motion between two bodies in contact. The friction of a fabric on itself or on another fabric influences significantly a fabric's performance and user's utility comfort, especially the socalled sensorial comfort. Generally, the coefficient of friction is determined for a given pair of materials. The aim of the present work was to investigate the influence of the structure of the seersucker woven fabrics on their frictional properties. Three variants of the seersucker woven fabrics of different repeat of the seersucker effect were the objects of the investigations. Three measuring elements were applied: made of aluminum and steel and covered with silicone. The obtained results confirmed the influence of the pattern of the seersucker effect on the values of friction coefficient. It was also stated that there are differences between the friction coefficients measured in the warp and weft directions of the seersucker woven fabrics. Values of friction coefficient between the seersucker woven fabrics and measuring elements were the highest for the measuring element covered by silicone. These values were several times higher than the values of friction coefficient measured using the measuring elements made of aluminum and steel.
\end{abstract}

\section{Keywords:}

Seersucker woven fabrics, friction coefficient, measurement, seersucker effect pattern

\section{Introduction}

Fabrics, woven or others, especially of clothing application very often are in direct contact with human skin. Owing to this fact, their surface properties, especially frictional ones, are crucial for utility comfort of their usage. Surface characteristic of the fabrics depends mostly on the properties of fibers from which the fabrics are made and on the geometric structure of the fabrics. The properties of fibers are determined by the kind of the polymer (raw material), thickness and shape of cross section of the fiber and the characteristic of fiber surface [1]. The surface geometry of the fabrics is determined by many factors such as the kind and thickness of yarn, weave, density of threads, and the way of finishing.

Fabrics' surface is usually characterized by two main properties: the surface friction and roughness [2]. Friction is defined as a force resisting a relative motion between two bodies in contact. There are two classical laws of friction for the solid surface in contact. The first law states that the frictional force $F$ is proportional to the load $R$ acting perpendicular to the surface. The proportionality constant $\mu$ is called as the coefficient of friction. The second law states that the frictional force is independent of the geometric contact area of bodies that are sliding on each other [3].
The friction of a fabric on itself or on another fabric influences significantly a fabric's performance and user's utility comfort, especially the so-called sensorial comfort [4]. The sensation is related to the mechanical interaction between the fabric and human skin.

Investigations showed that the coefficient of friction is constant for many solid materials but is generally not constant for textiles. Howell and Mazur introduced the friction index for the textile materials and showed that the friction index depends on the geometry of the asperities covering the surface and the nature of the deformation that the surfaces undergo [5]. Studies reported by Wilson [6] showed that the dynamic friction between fabrics in contact is related to the apparent contact between them. Moreover, experience confirmed a decrease in the friction coefficient with an increase in the normal force. Frydrych and Matusiak demonstrated that the static and dynamic friction coefficients are affected by the raw material, weave, and the way of finishing of the woven fabrics [7].

There are different methods of measuring the fabric friction. Nowadays, Kawabata Evaluation System is one of the most popular and accepted methods used all over the world to determine the surface characteristics of fabrics, both surface friction and surface roughness. The surface friction is also measured by pulling a block of mass over a flat rigid surface 
that is covered with the fabric being tested or using the inclined plane [8]. At the University of Minho (Portugal), the FRICTORQ measuring device has been developed for measuring the surface friction of textile materials [9]. Fracczak and Matusiak [10] measured surface friction of the seersucker woven fabrics using the 6-axes SI-40-20 Mini $40 \mathrm{~F} / \mathrm{T}$ force sensor mounted on the trolley of the linear module via an angle bracket. The authors applied measuring tips made up of different materials: aluminum, brass, and plastic. It was due to the fact that friction is usually between two bodies being in contact and friction force depends on the surface characteristics of contacting bodies.

In the next work, Fracczak et al. [11] investigated additionally the friction between the seersucker woven fabrics and cowhide leather simulating the human skin. They applied a cuboid that was placed on the fabric and attached with a lightweight and non-stretchable cord to the force sensor. Then, the cuboid was moved to a distance of $10 \mathrm{~cm}$. Thanks to the rigid attachment of one end, the fabric remained motionless and the cuboid slid on its surface. During the movement, the sensor measured a value of force with which the cuboid was pulled [11].

The aim of the present work was to investigate the influence of the structure of the seersucker woven fabrics on their frictional properties. For measurement of the friction coefficient, the method mentioned above [11] was applied. The current work discusses in details the principle of measurement and the problems that arose during the research.

\section{Materials and methods}

The seersucker woven fabrics of different structures were the objects of the investigation. The seersucker woven fabrics are characterized by an occurrence of the puckered and flat strips in the warp direction. This effect is created on the loom due to an application of two warp sets of different tensions. Totally, three variants of the seersucker woven fabrics were measured in the range of their surface friction. They differed from each other in the range of the repeat of the seersucker effect. The fabrics were manufactured from cotton yarns. In the experimental set of fabrics, three kinds of repeat of the seersucker pattern had been applied. Both warps, basic and puckering as well as weft, were made from the same yarn: 20 tex $x 2$ cotton. The following variants of pattern of the seersucker effect were applied:

- $\quad$ variant MM 1/1 $S$ - width of puckered and flat strips appropriately $5 \mathrm{~mm}$ and $8 \mathrm{~mm}$;

- variant MM 2/1 $\mathrm{S}$ - width of puckered and flat strips appropriately $9 \mathrm{~mm}$ and $18 \mathrm{~mm}$; and

- variant MM 3/1 $S$ - width of puckered and flat strips appropriately $11 \mathrm{~mm}$ and $41 \mathrm{~mm}$.

The pictures of the measured fabrics are presented in Figure 1.

The basic properties of the fabrics being investigated are presented in Table 1.

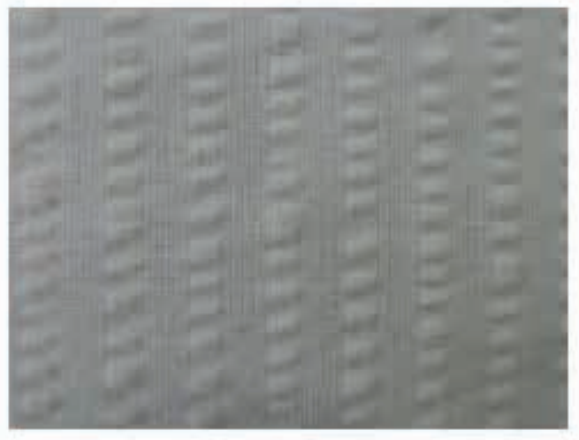

MM 1/1 S

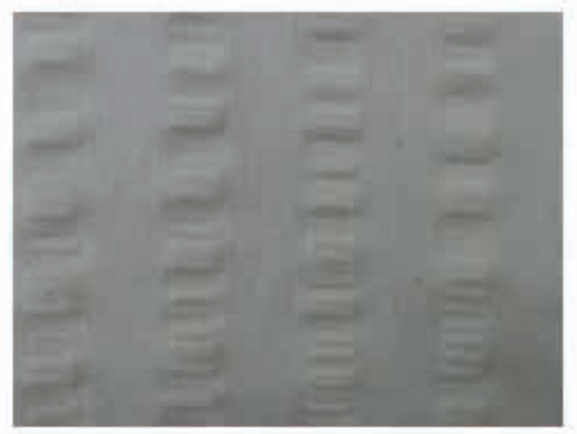

MM 2/1 S

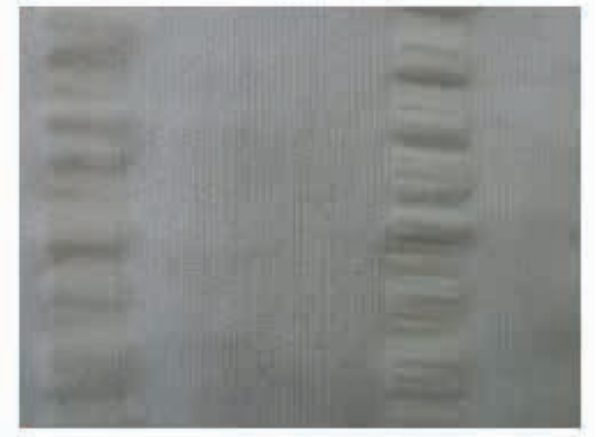

VMM $3 / 1 \mathrm{~S}$

Figure 1. Pictures of the seersucker woven fabrics being investigated.

Table 1. Basic structural properties of the investigated seersucker woven fabrics

\begin{tabular}{|c|c|c|c|c|}
\hline Weave - warp I & - & \multicolumn{3}{|c|}{ Plain } \\
\hline Weave - warp II & - & MM 1/1 S $2 / 2$ \\
\hline Repeat variant & - & 12.7 & MM 2/1 S & 12.6 \\
\hline Warp density & $\mathrm{cm}^{-1}$ & 11.4 & 11.5 & 11.4 \\
\hline Weft density & $\mathrm{cm}^{-1}$ & 212.9 & 207.8 & 11.4 \\
\hline Mass per square meter & $\mathrm{grm}^{-2}$ & 8.3 & 6.0 & 192.8 \\
\hline Take up - warp I & $\%$ & 49.8 & 48.8 & 5.2 \\
\hline Take up - warp II & $\%$ & 7.1 & 6.4 & 49.7 \\
\hline Take up - weft & $\%$ & & \\
\hline
\end{tabular}


Initial investigations of the surface friction of the seersucker woven fabrics were described by Frącczak et al. [11]. This work discusses in detail the principle of measurement and the problems that arose during the research. The tests were carried out on the same measuring stand that was used in initial investigations. The measuring stand is presented in Figure 2.

The fabrics were placed on the measuring table (1). On the one side, they were mounted on the holder (2), and then, they were gently smoothed by hand to remove unnecessary corrugation of the fabrics that could disturb the measurement of friction force. Next, a measuring mass (3) was placed on the fabric, which was attached to the sixth axial force sensor (4) (ATI Mini40 with measurement accuracy up to $0.01 \mathrm{~N}$ in the $X Y$ direction) using a non-stretchy and light thread. The force sensor was mounted on a trolley (5) of the servomechanism (6), which was moved along the fabric. The trolley was powered by the EC22 drive unit using the EPOS24/5 (7) amplifier. The drive set enabled smooth control of the trolley movement in the speed range of $0-6 \mathrm{~m} / \mathrm{min}$ with the accuracy of travel up to $0.01 \mathrm{~mm}$. The whole station was powered by a laboratory power supply (8). The friction measurements were carried out using a force sensor (4), which was connected to the computer via the amplifier (9). The measurements were recorded using a dedicated software provided by the manufacturer of the force sensor. The measurement was performed at a frequency of $1 \mathrm{kHz}$. In contrast, the data saved were averaged from 16 readings. Thus, in the space of $1 \mathrm{~s}$ of the measurement duration, approximately 62 measurement samples of force values were recorded.

Owing to the specificity of the seersucker fabrics, the measuring elements had a cut leading edge (Figure 3), which allowed the "gentle" entry of the measuring element into subsequent puckered strips of the fabric. Three different measuring elements were used for the tests: made of steel and aluminum and covered with silicone. All measuring masses were made as geometrically identical. Owing to the different densities of metals, the measuring masses had different weights. In order to balance the weights, appropriate weights were added to each of the measuring elements, thanks to which the total weight for all measuring elements was the same.

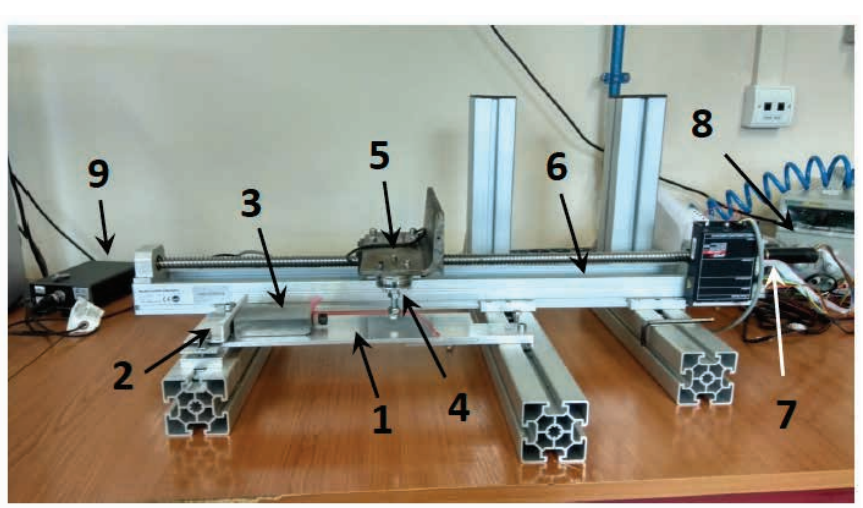

Figure 2. Measuring stand applied in the measurement of friction coefficient of the seersucker woven fabric [11].
The test consisted in dragging the measuring mass over the seersucker fabric on a distance of $10 \mathrm{~cm}$. Exemplary measurement results are shown in Figure 4.

On the basis of the results presented in Figure 4, it can be concluded that the initial and final phases are affected by coarse errors. The reasons of errors are dynamic relations between the fabric and the measuring element, static friction, and stresses in the seersucker woven fabric. A detailed analysis of this problem is presented in [11]. For further analysis, only the middle phase was considered, which is responsible for the part in which the friction was carried out freely. The high noise of the measurement is the result of entering subsequent puckered strips under the measuring mass. The noise in the measurement system is visible at the very beginning and end of the pulling test, where the measurement value is approximately 0 , and they are $\pm 0.02 \mathrm{~N}$. As mentioned earlier, only the middle phase was used for the analysis, which was averaged to one value using the following relationship:

$$
F=\sum_{i=1}^{n} f_{i}
$$

where $i=1,2, \ldots, n$ are the measuring points occurring in the middle phase of measurement and $n$ is the last measuring point in the middle phase.

Next, the coefficient of friction for a given pulling test was determined with the help of the commonly known equation:

$$
\mu=\frac{F}{N}=\frac{F}{m * g}
$$

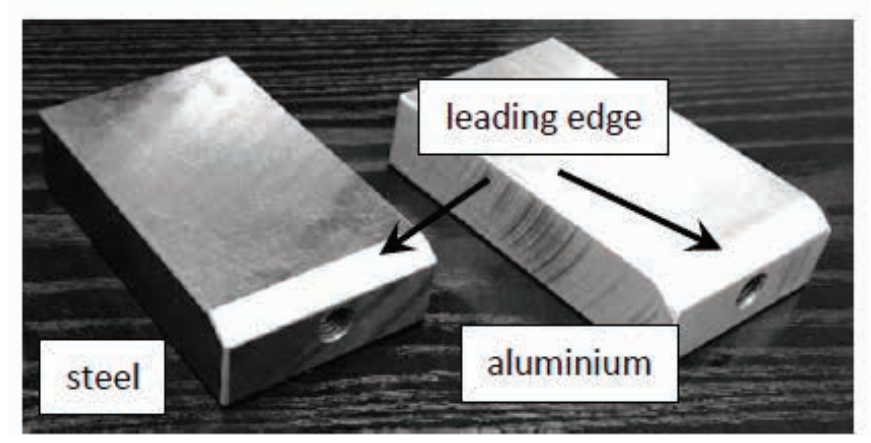

Figure 3. Measuring elements with cut leading edges.

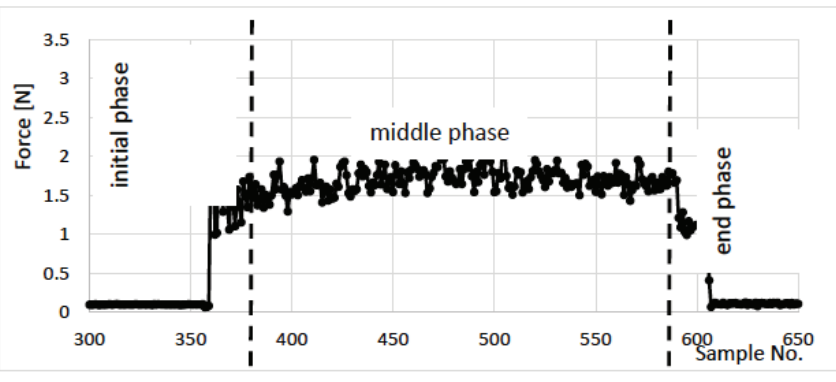

Figure 4. The values of the measured friction forces as a result of drawing the measuring mass on a distance of $10 \mathrm{~cm}$. 
where $N$ is the pressure force with which the cuboid acts on the fabric, $m$ is the mass of the measuring element, and $g$ is the gravitational acceleration (in the tests, it was assumed that $\left.g=9.81 \mathrm{~m} / \mathrm{s}^{2}\right)$.

The above operations were performed for three different seersucker woven fabrics shown in Figure 1. For each fabric, friction coefficient tests were performed both in the warp and weft directions. For each direction, measurement was performed for all combinations of friction pairs: fabric-measuring element. For each of the pairs and for each direction, 10 pulls were made on a $10 \mathrm{~cm}$ section. The results of the calculations are presented in Tables 2-4 and in Figures 5-7.

Analyzing the above data, it can be concluded that the coefficients of friction are different for different fabric-measuring element pairs. The highest friction coefficient occurs between silicone and MM 3/1 $S$ fabric in the warp direction whose average value was 1.33 . It needs to be highlighted that a coefficient of friction above 1 indicates that the pulling force must be greater than the pressure force. In turn, the lowest coefficient of friction was 0.83 for the pair: aluminum - MM $1 / 1 S$ fabric in the weft direction. It is worth emphasizing that in some cases, the values of the friction coefficient decrease with successive pulling (e.g. for aluminum or silicone). This can testify that the fabric could be slightly straightened. It is in agreement with Willsons' theory [6]. However, these changes in friction coefficient caused by fabric starching are very small.

Based on the tests carried out for the seersucker woven fabrics, it can be stated that for the majority of tests, the lowest friction coefficients occurred for MM $1 / 1 \quad S$ fabric, while for other fabrics, the values of determined friction coefficients are comparable.

Then, in order to check the impact of the pulling direction on the friction coefficient values, additional charts were made based on the data from Tables 2-4. Figure 8 presents a comparison

Table 2. The values of friction coefficient for the MM1/1 S fabric variant

\begin{tabular}{|c|c|c|c|c|c|c|c|c|c|c|c|c|}
\hline \multirow{2}{*}{ Material } & \multirow{2}{*}{ Direction } & \multicolumn{10}{|c|}{ Pull number } & \multirow[t]{2}{*}{ Average } \\
\hline & & 1 & 2 & 3 & 4 & 5 & 6 & 7 & 8 & 9 & 10 & \\
\hline \multirow{2}{*}{ Steel } & Warp & 0.22 & 0.23 & 0.23 & 0.23 & 0.22 & 0.23 & 0.22 & 0.23 & 0.23 & 0.22 & 0.225 \\
\hline & Weft & 0.23 & 0.22 & 0.23 & 0.22 & 0.22 & 0.22 & 0.22 & 0.22 & 0.22 & 0.22 & 0.222 \\
\hline \multirow{2}{*}{ Aluminum } & Warp & 0.20 & 0.20 & 0.19 & 0.19 & 0.19 & 0.20 & 0.20 & 0.19 & 0.19 & 0.19 & 0.194 \\
\hline & Weft & 0.19 & 0.19 & 0.19 & 0.18 & 0.18 & 0.18 & 0.18 & 0.18 & 0.18 & 0.18 & 0.183 \\
\hline \multirow{2}{*}{ Silicone } & Warp & 1.17 & 1.17 & 1.17 & 1.16 & 1.18 & 1.17 & 1.15 & 1.15 & 1.16 & 1.16 & 1.164 \\
\hline & Weft & 1.09 & 1.10 & 1.11 & 1.11 & 1.11 & 1.11 & 1.11 & 1.11 & 1.11 & 1.11 & 1.107 \\
\hline
\end{tabular}

Table 3. The values of friction coefficient for the MM2/1 S fabric variant

\begin{tabular}{|c|c|c|c|c|c|c|c|c|c|c|c|c|}
\hline \multirow{2}{*}{ Material } & \multirow{2}{*}{ Direction } & \multicolumn{10}{|c|}{ Pull number } & \multirow[t]{2}{*}{ Average } \\
\hline & & 1 & 2 & 3 & 4 & 5 & 6 & 7 & 8 & 9 & 10 & \\
\hline \multirow{2}{*}{ Steel } & Warp & 0.25 & 0.25 & 0.25 & 0.25 & 0.25 & 0.25 & 0.25 & 0.25 & 0.25 & 0.25 & 0.247 \\
\hline & Weft & 0.22 & 0.22 & 0.22 & 0.21 & 0.22 & 0.22 & 0.22 & 0.22 & 0.22 & 0.22 & 0.217 \\
\hline \multirow{2}{*}{ Aluminum } & Warp & 0.23 & 0.22 & 0.23 & 0.22 & 0.22 & 0.22 & 0.22 & 0.22 & 0.22 & 0.22 & 0.224 \\
\hline & Weft & 0.20 & 0.20 & 0.19 & 0.19 & 0.19 & 0.19 & 0.19 & 0.19 & 0.19 & 0.19 & 0.189 \\
\hline \multirow{2}{*}{ Silicone } & Warp & 1.30 & 1.30 & 1.28 & 1.29 & 1.31 & 1.30 & 1.30 & 1.30 & 1.31 & 1.31 & 1.299 \\
\hline & Weft & 1.26 & 1.23 & 1.22 & 1.22 & 1.22 & 1.21 & 1.22 & 1.21 & 1.21 & 1.21 & 1.222 \\
\hline
\end{tabular}

Table 4. The values of friction coefficient for the MM3/1 S fabric variant

\begin{tabular}{|c|c|c|c|c|c|c|c|c|c|c|c|c|}
\hline \multirow{2}{*}{ Material } & \multirow{2}{*}{ Direction } & \multicolumn{10}{|c|}{ Pull number } & Average \\
\cline { 3 - 14 } & & $\mathbf{1}$ & $\mathbf{2}$ & $\mathbf{3}$ & $\mathbf{4}$ & $\mathbf{5}$ & $\mathbf{6}$ & $\mathbf{7}$ & $\mathbf{8}$ & $\mathbf{9}$ & $\mathbf{1 0}$ & \\
\hline \multirow{3}{*}{ Steel } & Warp & 0.25 & 0.25 & 0.24 & 0.25 & 0.25 & 0.24 & 0.25 & 0.24 & 0.25 & 0.24 & 0.245 \\
\cline { 2 - 14 } & Weft & 0.25 & 0.24 & 0.24 & 0.24 & 0.24 & 0.24 & 0.24 & 0.23 & 0.24 & 0.24 & 0.238 \\
\hline \multirow{2}{*}{ Aluminum } & Warp & 0.22 & 0.22 & 0.22 & 0.22 & 0.21 & 0.22 & 0.22 & 0.21 & 0.22 & 0.21 & 0.216 \\
\cline { 2 - 13 }$y$ & Weft & 0.19 & 0.19 & 0.19 & 0.19 & 0.19 & 0.19 & 0.19 & 0.19 & 0.19 & 0.19 & 0.189 \\
\hline \multirow{2}{*}{ Silicone } & Warp & 1.40 & 1.37 & 1.36 & 1.34 & 1.35 & 1.34 & 1.34 & 1.35 & 1.29 & 1.20 & 1.335 \\
\cline { 2 - 13 } & Weft & 1.20 & 1.19 & 1.19 & 1.19 & 1.16 & 1.19 & 1.19 & 1.19 & 1.19 & 1.18 & 1.187 \\
\hline
\end{tabular}



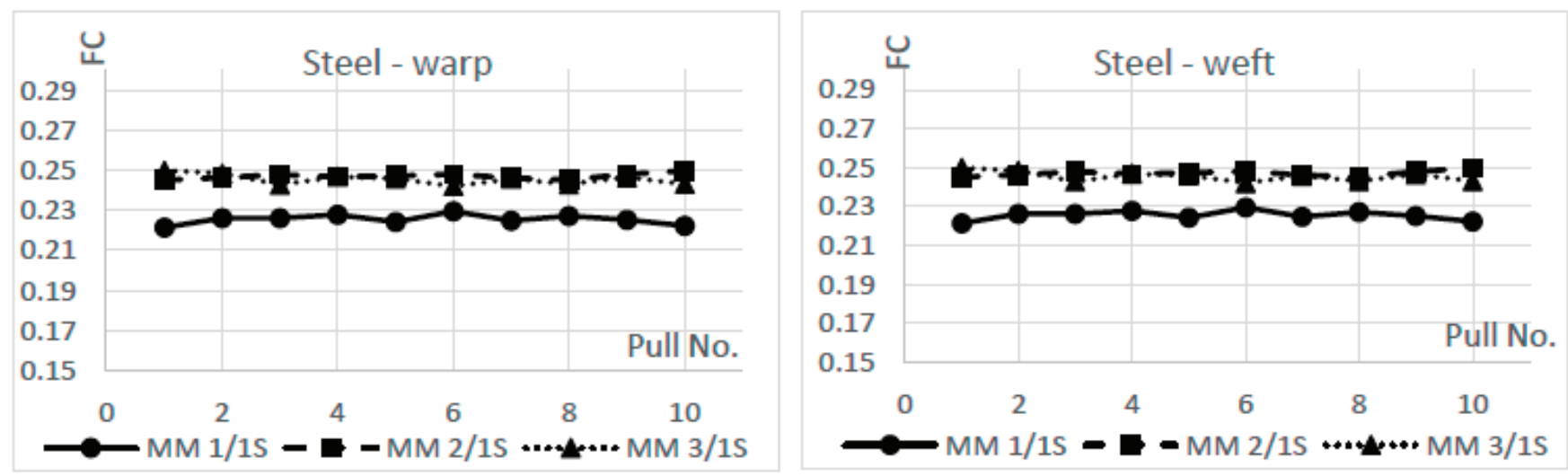

Figure 5. Values of friction coefficient for steel and three different fabrics in the warp and weft directions.

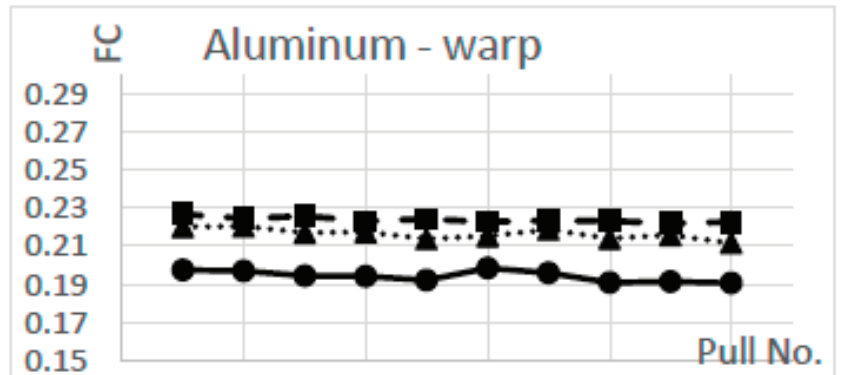

0.15

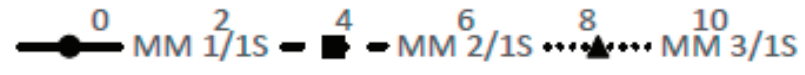

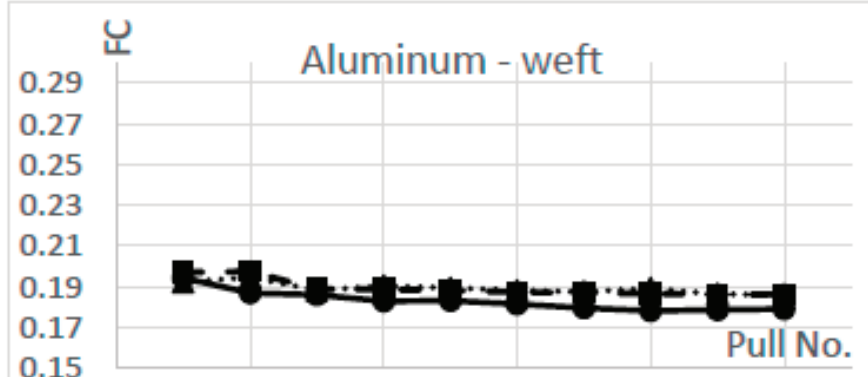

0.15

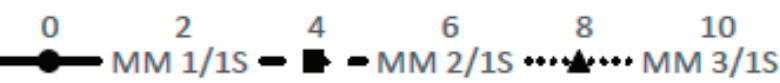

Figure 6. Values of friction coefficient for aluminum and three different fabrics in the warp and weft directions.
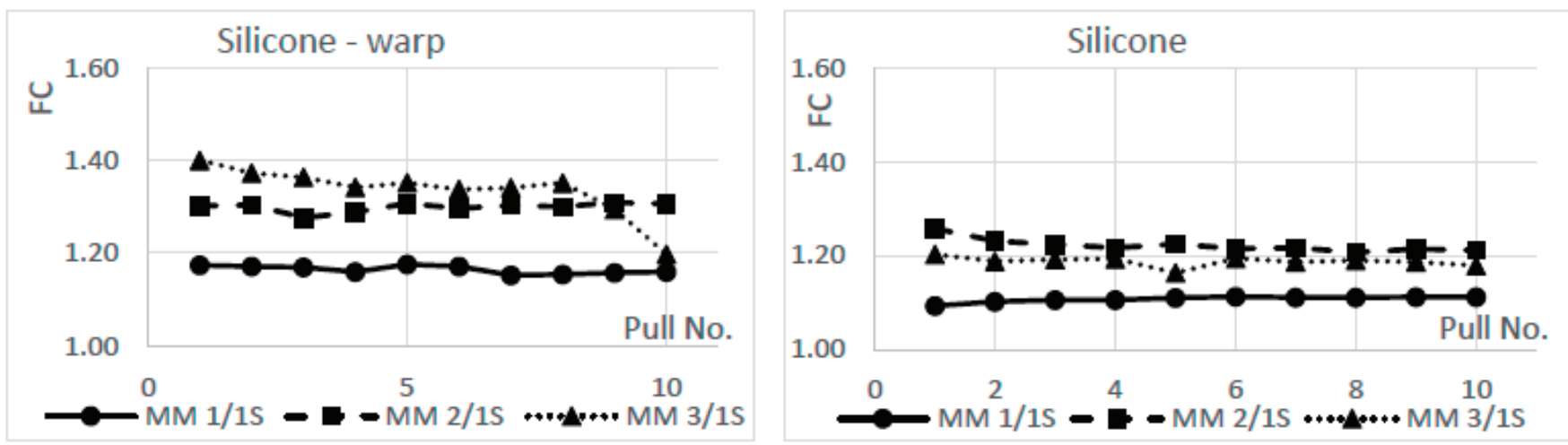

Figure 7. Values of friction coefficient for silicone and three different fabrics in the warp and weft directions.

of friction coefficients obtained while using the measuring elements made of aluminum and steel. The values of friction coefficients measured using the measuring element covered by silicone are much (several times) bigger than those obtained using aluminum- and steel-measuring elements. Owing to this fact, the results for the measuring element covered by silicone are presented in a separate graph (Figure 9).

The presented above charts show that the coefficients of friction in the weft direction are always lower than for the same friction pairs in the warp direction. This is due to the fact that in the warp direction, the measuring mass constantly overlapped the new puckered fragments because the measuring element moves along the puckered strips. These data are consistent with earlier presented data [1]. On the basis of the data presented in Figure 8 , it is clearly seen that for the aluminum- and steelmeasuring elements, the differences between the values of the friction coefficient measured in warp and weft directions are different for different patterns of the seersucker effect. In the 

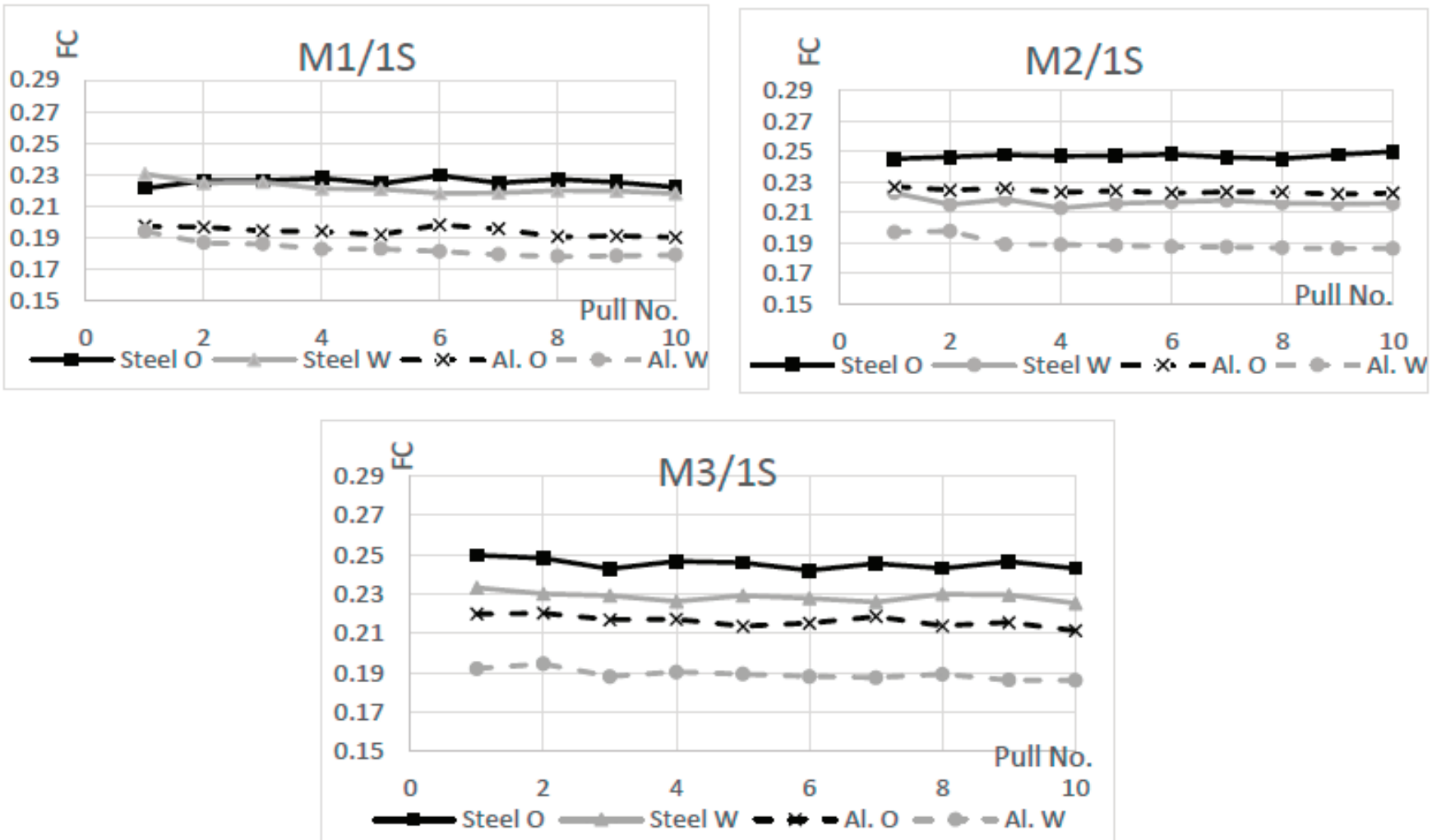

Figure 8. Friction coefficient test charts comparing different materials (steel and aluminum) and pulling directions for seersucker woven fabrics being investigated: $\mathrm{O}-$ in the warp direction and $\mathrm{W}-$ in the weft direction.

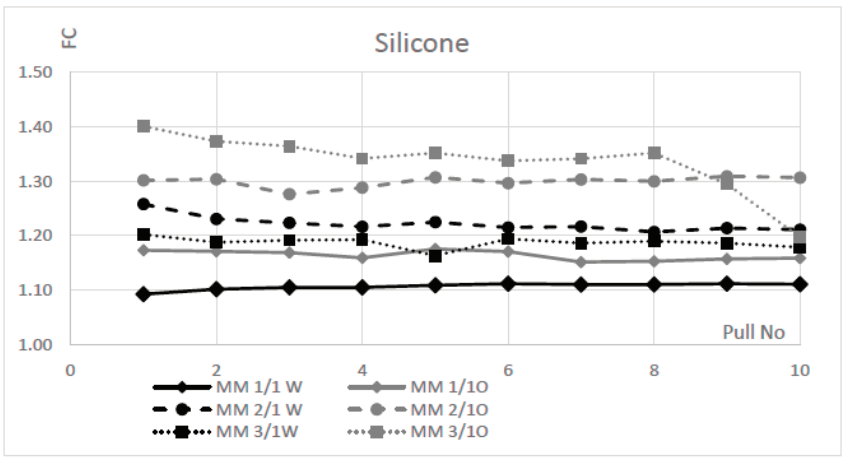

Figure 9. Friction coefficient test charts comparing pulling directions for pairs (silicone - seersucker woven fabrics being investigated): $\mathrm{O}$ in the warp direction and $\mathrm{W}$ - in the weft direction.

case of the MM 1/1 S variant, the difference in warp and weft directions is very small. While using the silicone-measuring element, differences in values measured in the warp and weft directions are big for all fabric variants. Also the influence of the pattern of the seersucker effect is observed. Differences between values of friction coefficient measured in the warp and weft directions are the lowest for the MM 1/1 S fabric variant and the highest for the MM 3/1 S variant.

\section{Summary}

Performed investigations confirmed the influence of the repeat of seersucker effect on values of friction coefficient of the seersucker woven fabrics. It was stated that the seersucker woven fabric with the narrowest puckered and flat strips (variant MM 1/1 S) is characterized by the lowest values of friction coefficient measured with all applied measurement elements: made of aluminum and steel as well as covered by silicone. Obtained results showed that the friction coefficient values measured using measuring element covered by silicone is several times higher than those measured using measuring elements made of aluminum and steel. In majority of cases, the values of frictions coefficient measured in the warp direction of the seersucker woven fabrics are higher than those measured in the weft direction.

\section{Acknowledgment}

This work is financed by the National Science Centre, Poland, in the frame of the project titled "Geometrical mechanical and biophysical parameterization of the three-dimensional woven structures", project No. 2016/23/B/ST8/02041. 


\section{References}

[1] Textile Metrology IV (Metrologia Włókiennicza IV - in Polish) (1973). Szmelter, W. (ed). WNT (Warsaw).

[2] Matusiak, M., Frącczak, Ł. (2015). Investigation of waviness of $3 D$ woven fabrics. In: Frydrych, I., Bartkowaik, G., Pawłowa, M. (eds.). Innovations in clothing design, materials, technology and measurement methods. Lodz University of Technology (Lodz), 166-182.

[3] Carr, W. W., Posey, J. E., Tincher, W. C. (2007). Frictional characteristics of apparel fabrics. Textile Research Journal, 59(3), 129-113.

[4] Rossi, R. (2005). Interaction between protection and thermal comfort. In: Scott, A. (ed.). Textiles for protection. Woodhead Publishing Ltd. (Cambridge, England), 233260.

[5] Howell, H. G., Mazur, J. (1953). Amonton's law and friction. Journal of Textile Institute, 44, T59.

[6] Wilson, D. (1963). A study of fabric-on-fabric dynamic friction. Journal of Textile Institute, 54, T143-T155.
[7] Frydrych, I., Matusiak, M. (2005). Effect of woven fabrics on the fabric hand of cotton and CO/PE fabrics assessed on the Instron tensile tester. In: Behery, H. M. (ed.). Effect of mechanical and physical properties on fabric hand. Woodhead Publishing in Textiles. Woodhead Publishing Ltd., 239-286.

[8] De Boss, A. (2005). Concepts and understanding of fabric hand. Chapter. In: Behery, H. M. (ed.). Effect of mechanical and physical properties on fabric hand. Woodhead Publishing Series in Textiles, 11-44.

[9] Lima, M., da Silva, L. F., Vasconcelos, R., Cunha, J. (2009). FRICTORQ, Design for the objective measurement of friction in $2 d$ soft surfaces. Proceedings of XIII Congreso Internacional De Ingeniería De Proyectos Badajoz.

[10] Fracczak, L., Matusiak, M. (2017). Investigation of surface friction of the seersucker fabrics. In: Frydrych, I., Bartkowiak, G., Pawłowa, M. (eds.). Innovations in clothing $3 D$ design, products, fashion, technologies and testing of clothing materials. Lodz University of Technology (Lodz), 235-249.

[11] Fracczak, L., Matusiak, M., Zgórniak, P. (2019). Investigation of friction coefficient of seersucker woven fabrics. Fibres \& Textiles in Eastern Europe, 2019, 27, 3(135), 36-42. 